\title{
Use of GERAM as Basis for a Virtual Enterprise Framework Model
}

\author{
J. Vesterager, L.B. Larsen, J.D. Pedersen, M. Tølle \\ Technical University of Denmark \\ Em: jve@ipt.dtu.dk \\ P. Bernus \\ Griffith University, Australia
}

Key words GERAM, Virtual Enterprise, framework model, industrial cases

\begin{abstract}
In the IMS-project Globeman21, the enterprise reference architecture GERAM was used as basis for creation of a virtual enterprise framework model. The model was used to map different industrial pilot projects, to classify virtual enterprise concepts, and as underlying structure for a virtual enterprise management methodology. The paper gives a survey of the use of GERAM and the results obtained.
\end{abstract}

\section{INTRODUCTION}

This paper builds on research work carried out in two IMS-projects: Globeman 21 and Globemen. The results presented are primarily based upon the work of the so-called Common Concept group of Globeman21 as well as the EU work packages on "virtual enterprise methodology support" and "generic models". The work continues in the ongoing Globemen project with the aim of producing a Virtual Manufacturing Enterprise Guidelines Handbook.

\section{GERAM AND THE VIRTUAL ENTERPRISE FRAMEWORK MODEL}

The purposes of the framework model were: 1) to create a reliable VEF by the use of GERAM [1] - e.g. ensuring validity of basic concepts and a sound communication basis; 2) to extend the VEF with specific VE- 
concepts, e.g. by relating it to already existing literature, and in this way to prove a general use of the VEF as a synthesizing 'tool'; and 3) to support more Globeman21-specific uses including, 3a) establishing a common foundation for comparison (mapping) of Globeman21 industrial pilot projects for general collection of experience, $3 b$ ) development and communication of industrial reference examples for use by other companies, and 3c) use of the framework model as a supporting skeleton for a first VE Management Methodology (VEMM).

\section{GERAM AND USED ELEMENT/COMPONENTS}

Elements of GERAM used so far in a systematic way are: the Process Oriented Concepts of Life Cycle (LC) and Life History, and recursiveness. As regards the View Concepts of GERAM, the Entity Purpose View ('management and control', and 'customer service and product') has also been applied systematically. In addition, the other View Concepts have been used as follows: Entity Model Contents Views (function, information, resource, and organisation) by referencing when needed, assuming knowledge of these topics. Correspondingly for the Genericity Dimension. The Entity Implementation View has not been used explicitly but is nevertheless dealt with through systematic application of a traditional Industrial Engineering work preparation approach to the preparation of VEs. Lastly, the Entity Physical Manifestation View component "software" was dealt with due to the fact that all industrial demonstrators were software projects.

\section{THE VE FRAMEWORK MODEL}

In Figure 1 the Globeman21 VE concept is shown. Companies assign competencies to a network in order to be able to create customer focused VEs satisfying customer needs (creating deliverables/solutions for the customer). Depending on customer needs, more contractors or sub-suppliers can be included in the different VEs without being members of the network.

The network is based on a relatively long term cooperation, whereas the VEs are dissolved, transferring experience back to network members, when the customer need is satisfied. Correspondingly, the same network can form many VEs, and a VE can produce many deliverables. In short, a VE is defined as "a customer solutions delivery system created by a temporary and reconfigurable ICT enabled aggregation of core competencies". The relationships between the partners in the network can vary from a loose relationship (by analogy with "Yellow Pages") to ownership as the other 
extreme. In Globeman 21 the industrial partner cases were quite focused networks, implying that the networks in question were relatively formalised ones of the types: partnership, strategic alliances, and ownership. In the near future, other types of network collaborations will probably also be possible, resembling the "Yellow Pages"-situation. This is for example due to global virtual markets for competencies, information standards as STEP APs for information integration, standard/reference models for contracts and a corresponding model-defined set-up, e.g. of joint ERP and engineering systems. In one sense this means looser networks, in another sense more prepared ones, due to common standards and reference models.

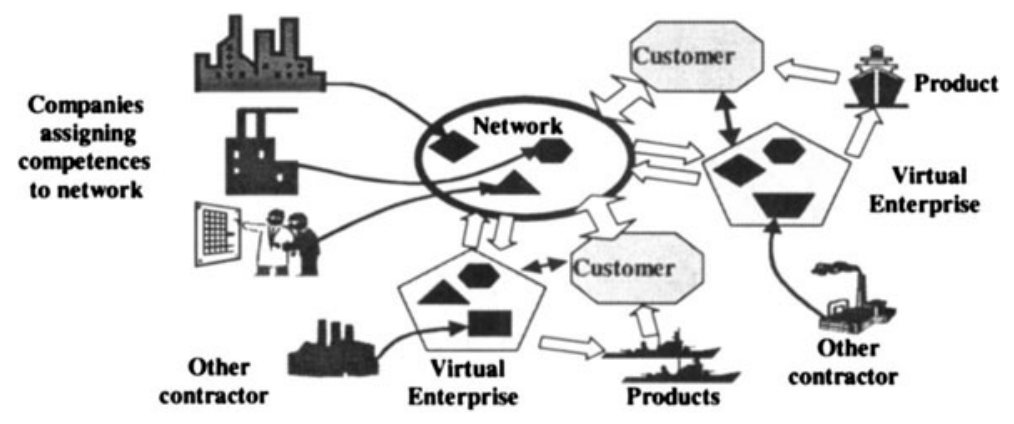

Figure 1 The Globeman21 virtual enterprise concept

In Figure 2 the GERAM based VE framework model is presented. The model consists of three recursive LCs: a network, a VE and a product LC (PLC). The double arrows between VE and PLC indicate that the deliverable corresponds to one or more phases of the PLC. The parts of the Entity Purpose View are indicated by shading of LC phases. For the sake of simplicity, the VEF does not include the LCs of the participating companies creating the network, for example by the formation of a common project.

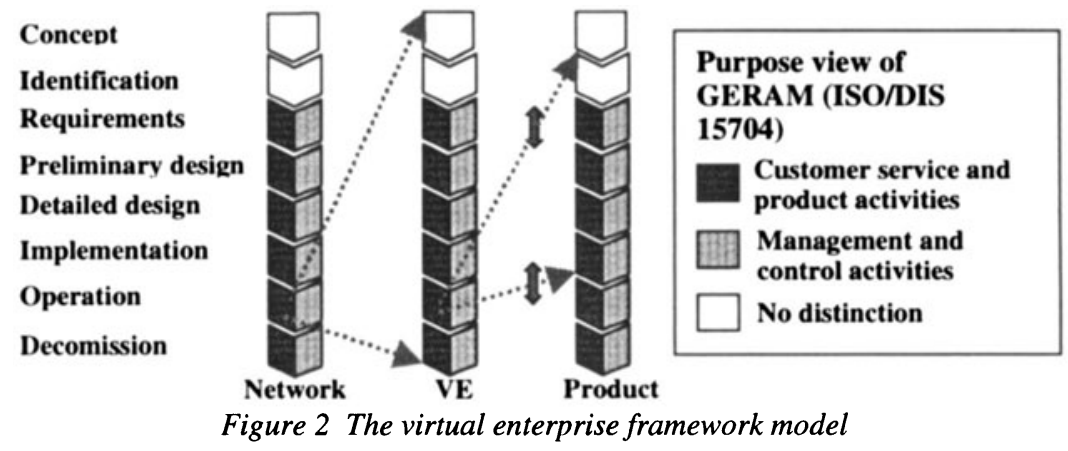




\section{USE AND RESULTS}

This chapter gives a summary of the results obtained. First, we present the way in which the framework can be used to classify concepts (description parameters) for VEs. Secondly, we show how the VEF was used to map Globeman21 industrial projects for comparisons and experience collection. Thirdly, we indicate how the VEMM was built by use of the VEF.

Table 1 Example of concepts (description parameters)

\begin{tabular}{|c|c|c|}
\hline & Examples of situational factors & Examples of design parameters \\
\hline & $\begin{array}{l}\text { - The necessity of: increasing flexibility in } \\
\text { different ways, specialising, decreasing } \\
\text { risks, reducing future uncertainty, } \\
\text { obtaining agility, increasing task } \\
\text { frequency, decreasing lead time, etc. } \\
\text { - Exploitation of ICT enablers (e.g. global } \\
\text { distributed concurrent engineering and } \\
\text { production) } \\
\text { - Social and cultural issues, e.g. } \\
\text { opportunity and barrier/threats } \\
\text { - In general: effectiveness and efficiency } \\
\text { considerations regarding competitive } \\
\text { situation }\end{array}$ & $\begin{array}{l}\text { - Member characteristics, ownership or } \\
\text { otherwise, type of agreements (e.g. IPR, } \\
\text { risk sharing), management structure (rules } \\
\text { and roles in network), etc. } \\
\text { - PLC coverage, types of VEs and } \\
\text { corresponding business processes to cover } \\
\text { (mission, vision, motivation) } \\
\text { - Preparation issues: degrees of } \\
\text { preparation to go for with respect to key } \\
\text { business processes, contractors, etc. } \\
\text { - Legal issues (e.g. leaving/entering } \\
\text { network) } \\
\text { - Handling of social and cultural issues }\end{array}$ \\
\hline 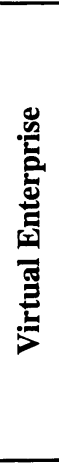 & $\begin{array}{l}\text { - Competitive VE lead time requirements } \\
\text { - Global distribution of partners and } \\
\text { customers } \\
\text { - Types of competencies needed to meet } \\
\text { customer demands } \\
\text { - Obtainable frequency of different VE- } \\
\text { types } \\
\text { - Situation of potential contractors (e.g. } \\
\text { ICT conditions, cultural issues) } \\
\text { - Available ICT enablers (e.g. standards, } \\
\text { vendor systems, communication systems) }\end{array}$ & $\begin{array}{l}\text { - Types and degrees of preparedness; } \\
\text { common models of VE creation processes } \\
\text { including temporary contractors (e.g. how } \\
\text { to qualify) and customers, and } \\
\text { corresponding development of ICT } \\
\text { applications } \\
\text { - Rules for VE-management (e.g. roles, } \\
\text { rules of leaving a VE) } \\
\text { - Rules for exposure of partner } \\
\text { competencies in operational delivery } \\
\text { systems } \\
\text { - Legal aspects (entering and leaving a } \\
\text { VE) }\end{array}$ \\
\hline 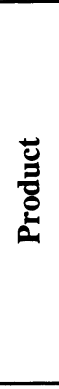 & $\begin{array}{l}\text { - Required PLC phases lead time } \\
\text { - Requested degree of innovation to } \\
\text { handle, stability of competency domains } \\
\text { - Geographical distribution of partners } \\
\text { - Available and usable ICT enablers (e.g. } \\
\text { PDM for distributed concurrent } \\
\text { engineering, ERP tools, standards) } \\
\text { - Obtainable frequency of different PLC } \\
\text { tasks } \\
\text { - Necessary PLC types and phases to cover }\end{array}$ & $\begin{array}{l}\text { - Types of PLCs and PLC-phases to cover } \\
\text { - Rules for PLC management, common } \\
\text { management and control models } \\
\text { - Preparedness: common product, facility } \\
\text { etc. models for instantiations (e.g. generic } \\
\text { product model, model driven CE) } \\
\text { - Relation: VE-type to carry out PLC-type } \\
\text { - Rules for customer involvement, conflict } \\
\text { resolution, exemption handling etc. } \\
\text { - Use of standards (e.g. demands on } \\
\text { temporary contractors) }\end{array}$ \\
\hline
\end{tabular}




\section{Description parameters for virtual enterprises}

Inspired by Mintzberg [3], description parameters were divided into situational factors (external conditions) and design parameters (options representing the solution space). Information sources were internal Globeman 21 project questionnaires, workshops, general experiences from projects, and a literature search reported in [2]. Table 1 gives examples of general concepts characterising the three LCs making up the VEF.

The description parameters in Table 1 are 'high level' planning concepts. Note that the table says nothing about when to consider the concepts in a VE-network engineering project - this question relates to the methodology.

Several already existing theories and corresponding concepts on enterprise management and planning not included here can be reused in this context, in order to describe the "to-be" situation, e.g. the concepts in the SCOR model on SCM [5] such as "purchased materials", "engineer-to-order product", and "make-to-order product". Consequently, the concepts can be further extended and refined, especially when focusing on a specific industry as, for example, one-of-a-kind manufacturing.

\section{Mapping of industrial cases}

As mentioned above, the VEF was used to map industrial projects (pilots) in order to extract experiences and in a systematic way present industrial reference examples. Referring to LC-phases, a distinction was made between where the pilots were engineered, and where they were used. Figure 3 shows the results in an almost pictogram-like manner. The arrows point to the phases where the developed pilot tools are used. For more information, see [4]. Here we only wish to state that the VEF proved very useful, especially considering the big differences between the mapped pilots.
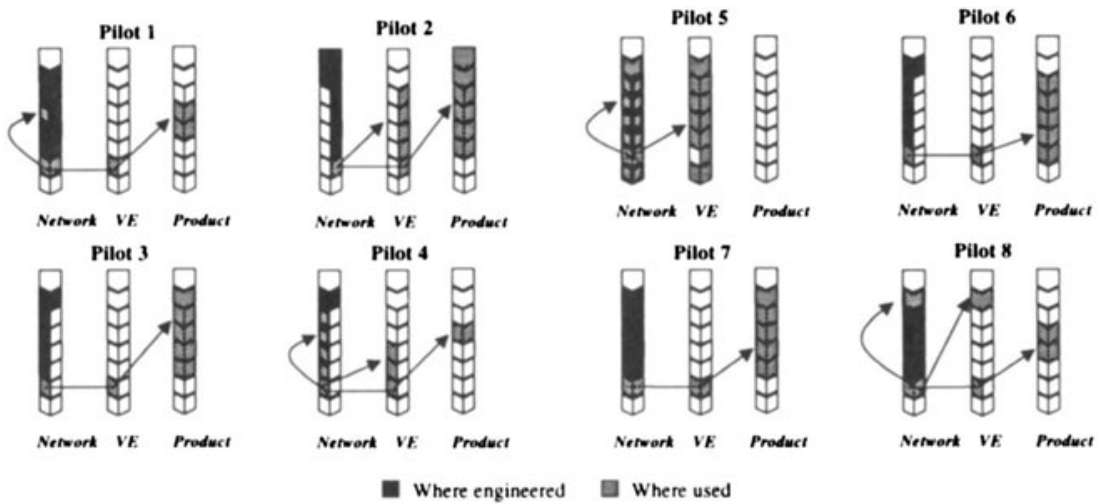

Figure 3 Mapping of Globeman2l industrial pilot projects 


\section{A VIRTUAL ENTERPRISE MANAGEMENT METHODOLOGY}

In order to introduce the developed VEMM it is appropriate to demonstrate, how the VEF unfolds in a life history perspective. Figure 4 shows an example. Space only allows a short explanation here. For more information, see [6]. The 3 LCs of the VEF are shown on top of each other in order to introduce the time dimension. Numbers 1, 2, 3, and 3a concern the first phases of the network LC, which result in the setting-up of the management and control part of the network. Notice that the network entity so to speak boots itself because the VEF as mentioned does not include the entity producing the network. 4 relates to the execution of preparation projects creating, for example, reference models or ICT tools to use in the operation of the network - here shown as triangles. At 5 the network is in operation. 6 demonstrates a customer identifying a product need. 7 and 8 shows the network setting up a VE through preparation projects, one of which prepares a tool to be used in the PLC phase 'preliminary design'. When operational, the VE creates a quotation, see 9 and 10. Subsequently, the VE is decommissioned - see 11. If the quotation is accepted, the network sets up a new VE producing the deliverable, see 12, 13 14. At 15 the product is handed over to the customer for operation and the VE is decommissioned. For the sake of completeness, 16 show that the network does not last forever.

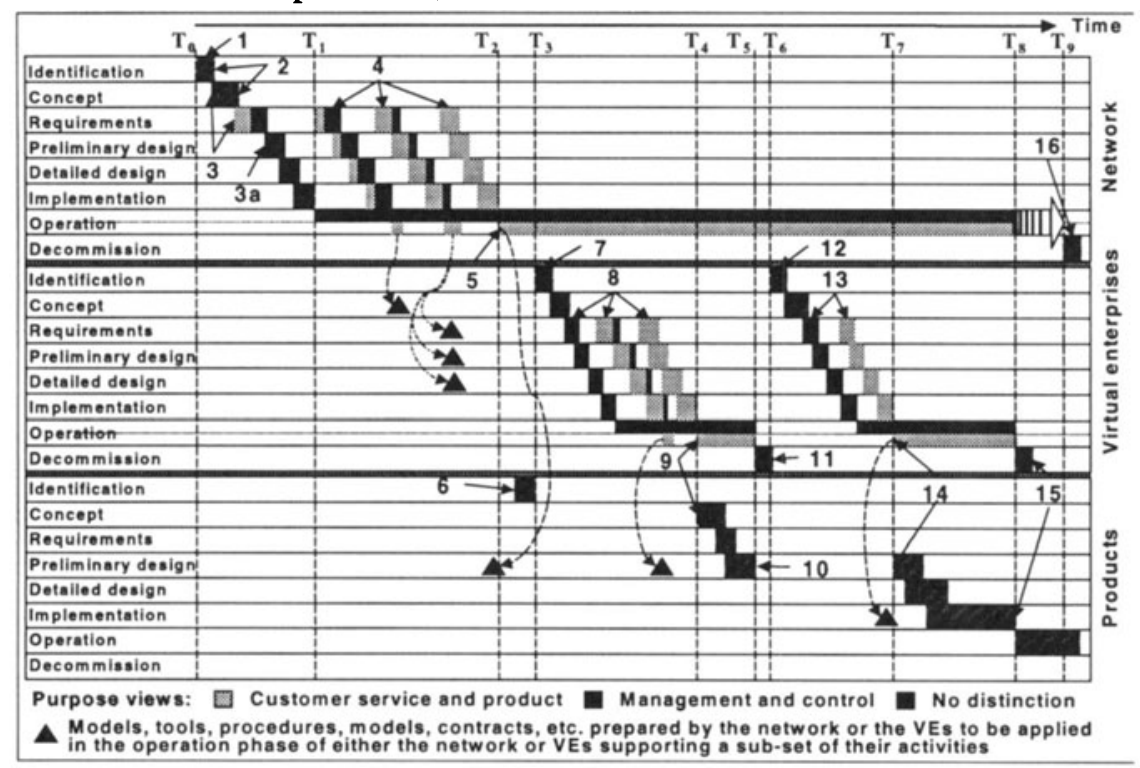

Figure 4 Example of life history 


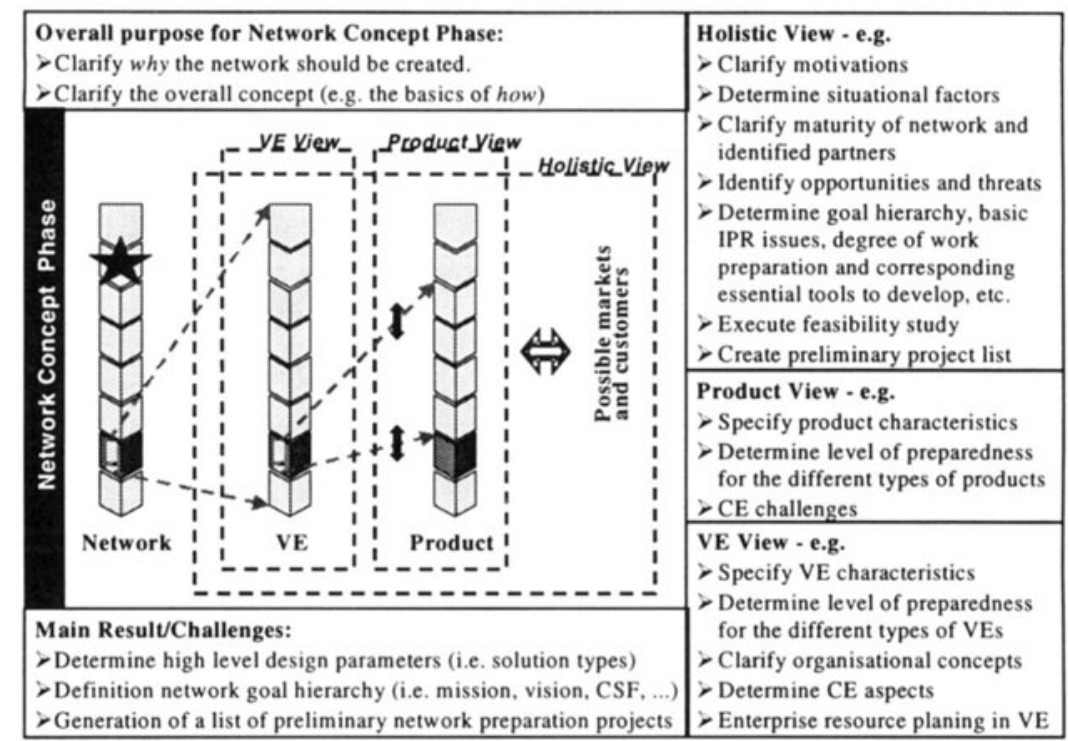

Figure 5 Methodology - the network concept phase

With this life history in mind, Figure 5 shows an extract of the VEMM. It gives examples of considerations to make in the concept phase of the network LC (see star). Well aware that planning and engineering considerations are iterative, the VEMM recommends first to take a holistic view followed by more focused analyses and decisions regarding the PLC and the VE.

\section{CONCLUSION}

Today much research work and many development projects address the problem of virtual enterprises. In our experience some of the key challenges are: establishment of joint reference models for a) global engineering, including its integrating infrastructure, and b) global management (e.g. resource and project planning). In our experience a unifying framework is crucial in order to ease communication across the many disciplines involved and across cultural borders, to enable a coherent and systematic collection and exchange of experiences, and to develop rewarding training programs.

The use of a virtual enterprise framework model mainly based on the enterprise reference architecture GERAM shows promise. The developed framework allowed - through a mapping of industrial projects - the demonstration of the relationships between the contributions of the large variety of seemingly unrelated projects within the consortium. Also, the 
framework served as a useful platform for the developed management methodology.

\section{ACKNOWLEDGEMENT}

The European Commission has sponsored this work. The authors wish to acknowledge the Commission for their support. Furthermore, we would like to express our gratitude and appreciation to all the Globeman21 and Globemen partners for their contribution during the development of results presented in this paper.

\section{REFERENCES}

[1] GERAM: Generalised Enterprise-Reference Architecture and Methodologies, ISO/DIS 15704, mainly developed by IFIP/IFAC "Task Force on Enterprise Integration" and IFIP WG 5.12 "Architectures for Enterprise Integration".

[2] Kaas-Pedersen C., Larsen L.B (eds.). (1998). Modelling Overview (public version), Report no D1.1, Globeman21, ESPRIT 26509, pp. 62. Department of Manufacturing Engineering, Technical University of Denmark.

[3] Mintzberg H. (1983). Structures in Fives: Designing Effective Organisations, Prentice Hall, 1983.

[4] Pedersen J.D., Vesterager J., Tølle M. Application of GERAM based Virtual Enterprise Framework - Results from IMS 95001/ESPRIT 26509, Proc. of the $6^{\text {th }}$ International Conference on Concurrent Enterprising, Toulouse, France, 28-30 June 2000, p. 139142.

[5] SCOR model. Supply-Chain Council Inc., 303 Freeport Road, Pittsburgh, PA 15215.

[6] Tølle M., Vesterager J., Pedersen J.D. A Methodology for Virtual Enterprise Management - Results from IMS 95001/ESPRIT 26509 Globeman21 project, Proc. of the $6^{\text {th }}$ International Conference on Concurrent Enterprising, Toulouse, France, 28-30 June 2000, p. 119-127. 